\title{
Analysis and Control of Fault Ride Through Capability Improvement PMSG Based on WECS Using Active Crowbar System During Different Fault Conditions
}

\author{
Altan Gencer \\ Department of Electrical and Electronics Engineering, Faculty of Engineering and Architecture, \\ Nevsehir H.B.V. University, \\ 50300, Nevsehir, Turkey \\ altangencer@nevsehir.edu.tr
}

\begin{abstract}
Recently, as wind energy has increased considerably in the electric power generation system, the wind turbines must maintain connected to the grid and improve the system stability during and after the grid faults. The enhancement of fault-ride through (FRT) capability of permanent magnet synchronous generator (PMSG) based on wind energy conversion system (WECS) is a vital issue. An active crowbar protection system in this paper is proposed to the improvement of FRT capability and the enhancement of the power quality of PMSG based on WECS system during and after the grid faults. The active crowbar in this paper is designed from a series resistor with an insulated gate bipolar transistor (IGBT) switch, unlike the passive crowbar, which has only one resistor. The active crowbar protects the power converters from the damaging effects of overcurrent during grid fault. The main aims of the active crowbar system are reduction of the amplitude of stator fault voltages, remains constant DC link voltage, general enhancement in all response of the PMSG, minimizing in the trigger time of the active crowbar. These aims are achieved with the introduction of the active crowbar between the machine side converter (MSC) and PMSG. The proposed protection system implemented a 1.5MVA PMSG based on WECS during different grid faults conditions using MATLAB/Simulation. The proposed protection system is compared with without protection system during different faults conditions and the validity of the proposed protection system is verified by simulation results.
\end{abstract}

Index Terms-Permanent magnet synchronous generator; Fault-ride through capability; Active crowbar; Wind energy conversion system.

\section{INTRODUCTION}

Wind energy is one of electricity generated methods from renewable energy source which has attracted a lot of interest in recent years [1], [2]. Permanent magnet synchronous generator has operation conditions such as at the low speed of wind, highest power-to-weight ratio in a direct drive, etc., so that it is widely used in the wind turbine [3], [4].

The number of wind farms increases day by day, so the grid connection situation of the wind turbine is more

Manuscript received 27 November, 2017; accepted 6 March, 2018. important than the past. Therefore, some countries must correct grid codes to maintain wind turbines connected with the grid during the grid fault. According to new grid codes, the wind turbine has to continue the connection with the grid even during the grid fault [5].

Grid code requirements are classified as dynamic and static requirements. Static grid code requirement contains power flow and steady-state capability at point of common coupling (PCC). Dynamic grid code requirement contains requested responses of the permanent magnet synchronous generator (PMSG) during grid fault. Both dynamic grid code and static grid code requirements are regulation of power factor, the operating range of voltage, fault ride-through or low voltage ride through (LVRT) capability [6], [7].

Grid faults cause overcurrent on stator windings, overvoltage on DC link and torque oscillations. Moreover, the grid faults cause destruction of the machine side converter (MSC), DC-link capacitor, and mechanical parts [8]. PMSG cannot maintain the connection with the grid without the proper control and protection system during the grid faults. The purpose of the protection system is to limit the mechanical and electrical variables to protect the system from damage during grid faults and PMSG can also maintain the connection with the grid during the grid faults [9].

There are several proposed protection systems to improvement of the fault ride through capability of the PMSG based wind energy conversion system (WECS) in the literature [10]-[12]. These protection approaches are presented as the most successful fault-ride through (FRT) strategy. Moreover, the DC link voltage makes easier to separately analyse by grid-side converters. However, most of them consist of symmetrical fault control system and components. These introduced systems are only applicable in symmetrical fault situations. On the other hand, the proposed active crowbar system in this paper provides a full control for the PMSG during symmetrical and unsymmetrical grid fault. In this proposed scheme, the control structure is also implemented instead of using the extra software. 
Crowbar circuits are two types as passive crowbar and active crowbar. A passive crowbar has a simple structure consisting of either resistance or thyristors. The passive crowbar does not have ability to open and close during high voltage, and it only has the closing feature. The passive crowbar allows re-open after the high voltage is extinguished [13]. The active crowbar consists of the transistor, insulated gate bipolar transistor (IGBT), gate turn-off (GTO) thyristor, used for switching purposes. The active crowbar has ability to open and close during high voltage. The active crowbar is designed to prevent the MSC of doubly fed induction generator (DFIG) from damaging effects of the high voltage during grid fault. The active crowbar has a full control structure by means of a semiconductor switch while the passive crowbar has a limited operation structure. Thus, the generator can maintain the power supply to load and can continue the connection with the grid even during the grid fault by means of an active crowbar [7].

This paper presents enhancement of fault-ride through capability of permanent magnet synchronous generator based on wind energy conversion system with active crowbar protection circuit during different fault conditions. The active crowbar in this paper is designed from a series resistor with a semiconductor switch, unlike the passive crowbar, which has only one resistor. Aim of the active crowbar is to continue the connection of PMSG with the grid during grid fault and maintain uninterrupted power supply for the load. The active crowbar protects the power converters from the damaging effects of overcurrent during the grid fault. The main aims of the active crowbar system are reduction of the amplitude of stator fault voltages, remains constant DC link voltage, general enhancement in all response of the PMSG, minimizing in the trigger time of the active crowbar. These aims are achieved with the introduction of the active crowbar between the MSC and PMSG. The proposed system implemented a WECS based 1.5MVA PMSG for different grid fault conditions using MATLAB/Simulation. The proposed system is compared with without protection system for different grid fault conditions and the validity of the proposed system is verified by simulation results.

The rest of the paper is organized as follows; Section II summarizes WECS system. Proposed active crowbar system for FRT improvement capability of the PMSG based on WECS is introduced in Section III. Design of active crowbar circuit is given in Section IV. The comparative results of simulation studies the efficiency of the proposed active crowbar system are presented in Section V. Finally, conclusions are given in Section VI.

\section{WIND ENERGY CONVERSION SYSTEM}

The configuration of variable speed WECS based on PMSG is given in the Fig. 1. Wind energy conversion system converts from wind power to electrical power. Wind turbine consists of generator, blade, power electronics, and control systems. Several generator types use in the wind turbine. Recently, PMSG is widely used in these types due to PMSG has several behaviours such as generated from low wind speed, operated without any gearbox. MSC converts from generator generated $\mathrm{AC}$ voltage to DC link voltage and then, grid side converter (GSC) converts from DC link voltage to 3 phases AC voltage. Measured variables are the currents, voltages, active and reactive power, and etc. Inputs of the control systems are these measured variables. Control systems correct both converter systems and grid power supplied. Transformer increases output voltage value of GSC, which is necessary to connect to the grid.

\section{A. Wind Turbine Characteristics}

The mechanical power of any WT is represented in (1). [14]

$$
P_{m}=\frac{1}{2} \rho A C_{p}(\lambda, \beta) V_{\omega}^{3} .
$$

Equation (1) has 6 variables, namely the power coefficient $C_{p}$, the area swept by blade $A$, the air density $\rho$, a nonlinear function of the TSR $\lambda$, pitch angle $\beta$, and the wind speed $V_{\omega}$. Equation of the $\lambda$ is given in (2)

$$
\lambda=\frac{\omega_{r} r}{V_{\omega}}
$$

where $\omega_{r}$ represents the rotor speed, $r$ represents blade radius. $C_{p}$ in (3) is obtained with configurable $\beta$ according to producer data [14].

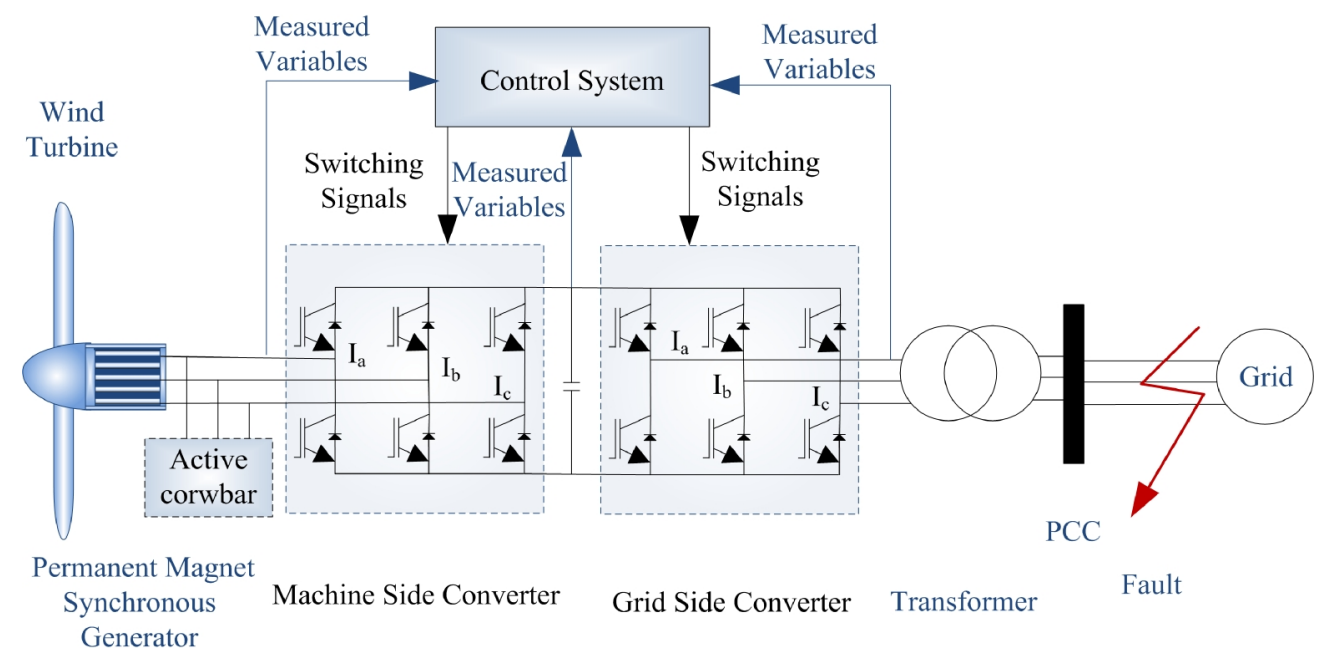

Fig. 1. Configuration of variable speed WECS based PMSG. 


\section{B. Mathematical Model of PMSG}

The voltage equations of PMSG are given in (8), where $R_{s}$ is resistance of stator and $L_{s}$ is inductance of the stator, the $v_{s}$ is terminal voltage generated by PMSG, the $\omega_{e}$ is the electric angular frequency are described in (3) and (4) [14]-[17]:

$$
\begin{gathered}
v_{s d}=R_{s} i_{s d}+L_{d} \frac{d i_{s d}}{d t}-\omega_{e} \psi_{s q}, \\
v_{s q}=R_{s} i_{s q}+L_{q} \frac{d i_{s q}}{d t}+\omega_{e} \psi_{s d} .
\end{gathered}
$$

The induced flux linkages in the stator (dq frame) are given in (5) and (6):

$$
\begin{gathered}
\psi_{s d}=L_{d} i_{s d}+\psi_{f}, \\
\psi_{s q}=L_{q} i_{s q},
\end{gathered}
$$

where $\psi_{s d}$ and $\psi_{s q}$ are the flux linkage, $L_{s}$ and $L_{q}$ represent stator inductances in the $d q$ frame, $i_{s d}$ and $i_{s q}$ represent generator $d q$ frame currents, $\psi_{f}$ represents flux linkage in the permanent magnets.

Voltage and current equations of the $d$ and $q$ loops are obtained in (7) and (8):

$$
\begin{gathered}
v_{s d}=R_{s} i_{s d}+L_{d} \frac{d i_{s d}}{d t}-\omega_{e} L_{q} i_{s q}, \\
v_{s q}=R_{s} i_{s q}+L_{q} \frac{d i_{s q}}{d t}+\omega_{e} L_{d} i_{s d}+\omega_{e} \psi_{f},
\end{gathered}
$$

where $v_{s d}$ and $v_{s q}$ are voltages of the $d$ and $q$ loops in the stator, respectively, the voltages of the $v_{s d}$ and $v_{s q}$ are utilized to generate the reference three-phase sinusoidal voltage, $i_{s d}$ and $i_{s q}$ represent currents of $d$ and $q$ loops in the stator, respectively, $R_{s}$ is resistor of the stator, $L_{d}$ and $L_{q}$ represent inductances of $d$ and $q$ loops in the stator, respectively, $\omega_{e}$ is electrical angular of the PMSG.

\section{Proposed Active Crowbar Protection System}

An active crowbar protection system enhances FRT capability of wind turbine-based PMSG. An active crowbar circuit system of the PMSG is given in Fig. 1. Due to the magnetic coupling between the stator and the rotor of the PMSG, the high stator transient current is excited. For this reason, the machine side converter is short-circuited to protect the power converters by an active crowbar circuit which includes resistor and semiconductor switch. The value of the active crowbar resistor is dependent on the generator data, and hence, the active crowbar resistance value of the any the generator has to be reselected for the new. Aim of the active crowbar is to limit the stator overcurrent to protect the power converters during grid fault. When the active crowbar circuit is active, the machine side converter is disabled, and the capability to independently control of the active and reactive power is lost. In addition, the active crowbar protection system short-circuits the grid side convertor to protect from high transient stator currents. The control methods of the machine side and grid side converters adjust active and reactive power of the system during grid fault. The resistors, thyristors, TRIAC, IGBTs use as switch devices in the active crowbar protection circuit which is a specially designed electrical circuit. The active crowbar protection system is costly to installation and operation, but these costs are cheaper than other protection systems.

\section{A. MSC Control}

A block diagram of the MSC control is given in Fig. 2. The block diagram of the MSC control consists of the active and reactive power control system. The stator currents are carried on a three-axis, two-axis system by the Clarke Transform. Moreover, the stator current is represented on a two-axis orthogonal system. This two-axis rotating coordinate system is called the $\alpha-\beta$ axis. The next step is to convert into another two-axis system, called the $\mathrm{d}-\mathrm{q}$ axis by the Park Transform. The stator reactive power $Q$ is determined by the $\mathrm{d}$-axis component, while the stator active power $\mathrm{P}$ is determined by the q-axis component [18]. This control block diagram consists of a very fast inner loop for current tracking, while this control block diagram consists of a relatively slow outer loop for active and reactive power regulation. The inner loop generates voltage commands for pulse width modulation (PWM) converters by means of two proportional-integral (PI) controllers. On the other hand, the outer loop generates reference current command for the inner loop [19]. The reference reactive power $\left(Q_{r e f}\right)$ is set to zero, which is normally sufficient for reactive power compensation in a wind farm. In Fig. 2, reference voltages $\left(V_{s d}^{*}\right.$ and $V_{s q}^{*}$ ) is added to enhance the transient response, are expressed by:

$$
\begin{gathered}
V_{s d}^{*}=V_{\text {sdref }}-\omega_{e} L_{q} i_{s q}, \\
V_{s q}^{*}=V_{s q r e f}+\omega_{e} L_{d} i_{s d}+\omega_{e} \psi_{f} .
\end{gathered}
$$

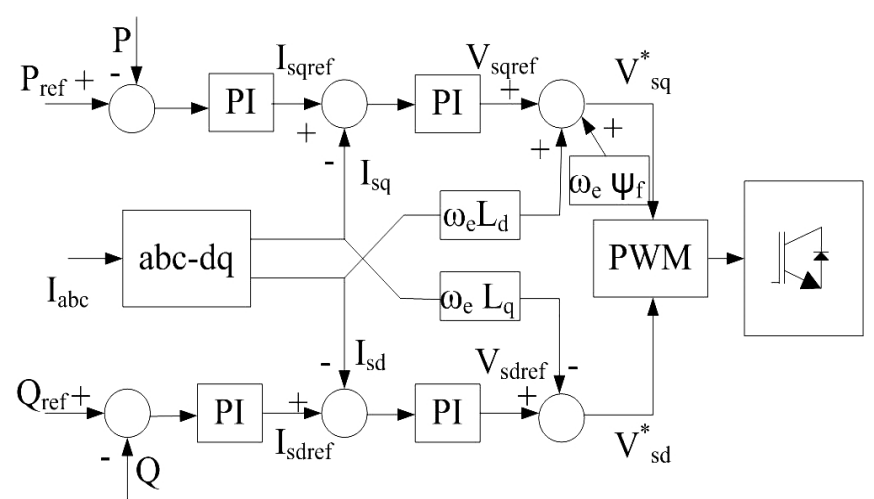

Fig. 2. Control block diagram of the MSC for PMSG.

\section{B. GSC Control}

A block diagram of the GSC control is given in Fig. 3. The block diagram of the GSC control consists of the DC link voltage and reactive power control system. The GSC control regulates the reactive power of the power system and value of DC link voltage. The stator reactive power $(Q)$ is determined by the q-axis component, while the DC Link voltage $\left(V_{d c}\right)$ is determined by the d-axis component. This control block diagram consists of a very fast inner loop for 
voltage tracking, while this control block diagram consists of a relatively slow outer loop for reactive power regulation. The GSC rating is almost $25 \%-30 \%$ of the rating of the generator. The reference reactive power $Q_{\text {ref }}$ is set to zero, which is normally sufficient for reactive power compensation in a wind farm [19], [20]. In Fig. 3, reference voltages $\left(V_{d}^{*}\right.$ and $\left.V_{q}^{*}\right)$ are added to enhance the transient response, expressed by:

$$
\begin{gathered}
V_{d}^{*}=V_{\text {sdref }}-\omega_{e} L_{q} i_{s q}+E \\
V_{q}^{*}=V_{\text {qref }}+\omega_{e} L_{d} i_{d} .
\end{gathered}
$$

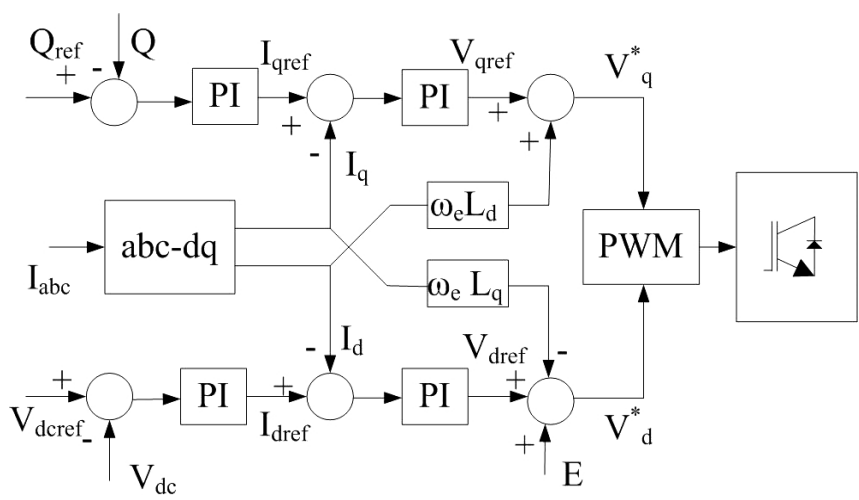

Fig. 3. Control block diagram of the GSC for PMSG.

\section{ACTIVE CROWBAR CIRCUIT}

An active crowbar topology is given for PMSG based on wind turbine in Fig 4. This topology is mostly used in literature. It consists of a diode bridge, a self-turn-off device IGBT, and a DC crowbar resistor [21].

The stator overvoltage causes a destruction of the MSC in a few milliseconds during grid fault. An active crowbar circuit is used to prevent from this destruction. Active crowbar operates by the means of the gate turn on and off signals of the IGBT. In order to protect against destruction from overvoltage in stator, a trigger signal is given to the IGBT and the protection circuit is activated. The MSC is idle with devices that have the self-shutdown property during activation. Therefore, the MSC is protected from the damaging effects of overvoltage.

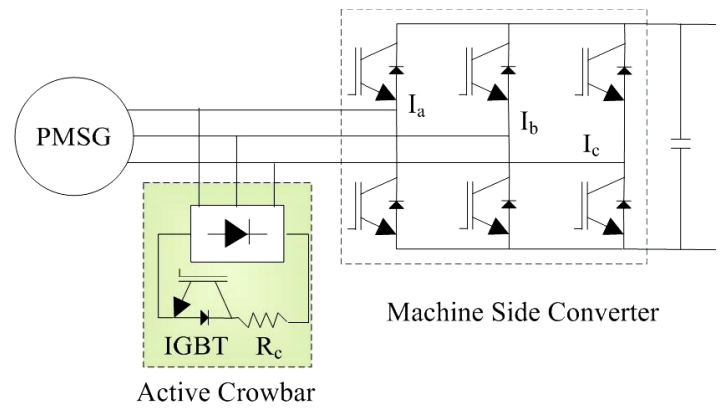

Fig. 4. An active crowbar circuit.

When the stator voltage falls below the pre-set threshold, the IGBT is deactivated. Then, a well-designed procedure for quick re-operation of MSC is applied. When grid voltage returns to normal level, the active crowbar circuit turn off by the power electronic device. Then the wind power system runs at normal operation condition.
The high currents follow on the IGBT in the active crowbar circuit during grid fault. Therefore, the current capability of the IGBT in the active crowbar circuit is selected several times higher than the current values of the IGBT in the power converter.

\section{A. Economic Feasibility of the Active Crowbar}

The costs of different types of protection methods are given in Table I. According to values in Table I, the lowest cost belongs to the traditional crowbar method. After the traditional crowbar method, the least cost is the proposed active crowbar system. The abilities of different types of protection methods are given in Table II. Although traditional crowbar costs are more appropriate than the proposed active crowbar system, performance of traditional crowbar is low. Proposed active crowbar system can be applied to both symmetrical and unsymmetrical fault conditions. Hence, the application of the proposed active crowbar system is easy and the process is very simple [7].

TABLE I. THE COSTS OF DIFFERENT TYPES OF PROTECTION

\begin{tabular}{|c|c|}
\multicolumn{2}{|c|}{ METHODS [7]. } \\
\hline Protection methods & Price (US\$) \\
\hline Classical dynamic voltage restorer & $67,299.99$ \\
\hline Low cost dynamic voltage restorer & $36,778.79$ \\
\hline Static synchronous compensator & $210,000.00$ \\
\hline Traditional crowbar & $10.00-80.00$ \\
\hline Active crowbar & 100.00 \\
\hline Classical dynamic voltage restorer & $67,299.99$ \\
\hline
\end{tabular}

\begin{tabular}{|c|c|c|}
\hline \multicolumn{3}{|c|}{ METHODS [7]. } \\
\hline $\begin{array}{c}\text { The abilities of } \\
\text { protection methods }\end{array}$ & $\begin{array}{c}\text { Traditional } \\
\text { crowbar }\end{array}$ & Active crowbar \\
\hline $\begin{array}{l}\text { Limit current of } \\
\text { stator (p.u) }\end{array}$ & $<2.4$ & $<2.0$ \\
\hline $\begin{array}{c}\text { Operation condition } \\
\text { of MSC }\end{array}$ & Blocked & Partly maintained \\
\hline $\begin{array}{l}\text { Limit voltage of the } \\
\text { DC link (p.u) }\end{array}$ & $<1.35$ & $<1.30$ \\
\hline Comment & $\begin{array}{l}\text { Useful for } \\
\text { symmetrical } \\
\text { fault only }\end{array}$ & $\begin{array}{l}\text { Useful for symmetrical } \\
\text { fault and un symmetrical } \\
\text { fault }\end{array}$ \\
\hline
\end{tabular}

TABLE II. THE ABILITIES OF DIFFERENT TYPES OF PROTECTION

\section{B. Choice of the Active Crowbar Resistance}

An active crowbar protection circuit changes from a reactive power source to a reactive power load during a grid fault. The active crowbar is placed between the stator windings and the MSC. The active crowbar circuit is modelled as a connected IGBT with resistance $R_{c}$ in MATLAB/Simulink. The IGBT is triggered by the turn ON/OFF control strategy.

The active crowbar resistance value can affect the current control behaviour during the grid fault. The large crowbar resistance provides better damping of overcurrent in the stator and reduced torque oscillation. It also reduces reactive power consumption the least. On the other hand, a large crowbar resistance can cause high voltage on the stator windings upon deactivation, which causes stress on the stator windings [21].

\section{Simulation Results}

The block diagram of the PMSG based on WECS system 
is given for verification of the active crowbar protection system in Fig 1.

Two different cases of symmetrical and unsymmetrical faults are analysed using an active crowbar design circuit and PMSG-based WECS in the Matlab/Simulink.

The MSC is implemented with the active crowbar protection system to improve operation conditions of the PMSG based on WES during different grid faults. The MSC is to improve reactive power requirement during grid fault. In addition to, the MSC is to extract maximum power from the wind turbine.

The GSC maintains a nearly constant voltage value of the Dc link voltage and the voltage at the PCC maintains the same value. In addition to, the GSC is to quickly correct the required reactive power for the system. Active crowbar is designed for the switch semiconductor device and resistance. The overcurrent cannot reach the stator by means of active crowbar during grid fault. Therefore, active crowbar protects the stator windings and MSC from the damaging effects of overcurrent.

\section{A. Scenario 1}

The simulation results of PMSG is observed without and with the active crowbar during a symmetrical $3-\Phi$ to the ground fault between three phase and ground. In Fig 5(a), three line fault is applied between $4.0 \mathrm{~s}$ and $4.1 \mathrm{~s}$. The simulation results for the FRT performance PMSG system with a three-phase symmetrical fault are given in Fig. 5. As shown in Fig. 5, when the grid fault occurred and the active crowbar protection circuit is not triggered, the voltage at PCC almost reduces to zero.
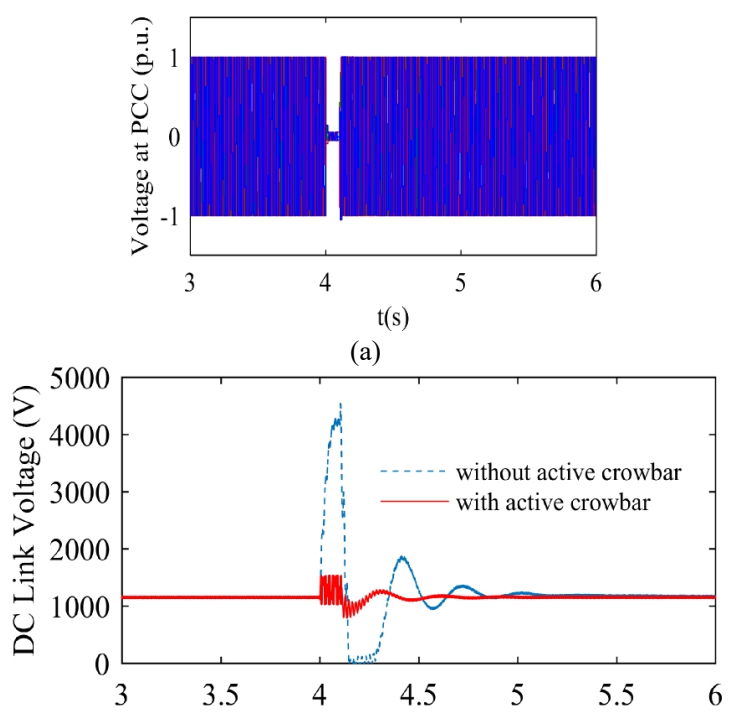

(b)

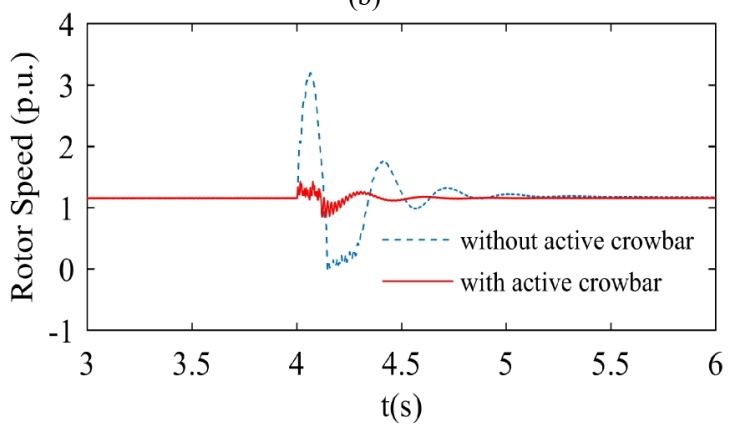

(c)

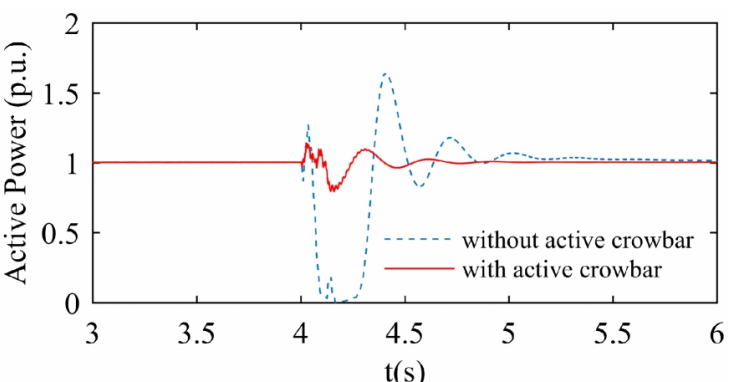

(d)

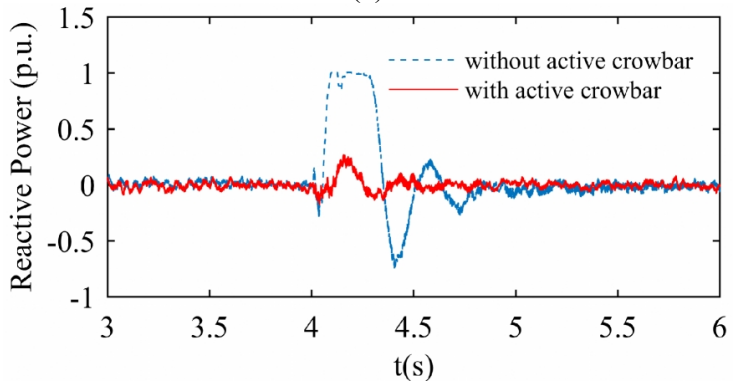

(e)

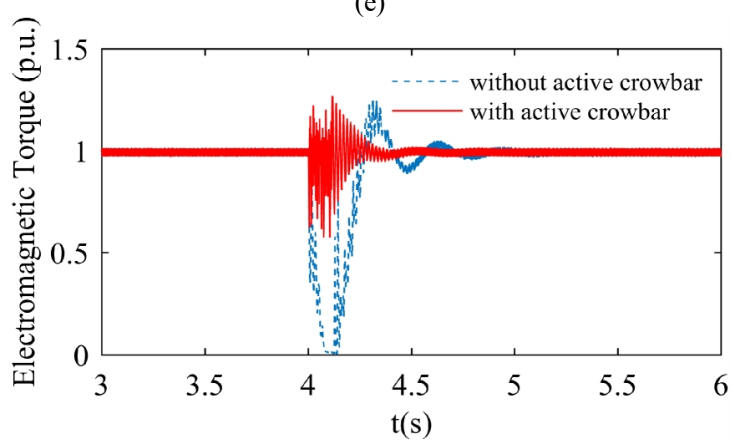

(f)

Fig. 5. Dynamic response of a 1.5 MVA PMSG with and without active crowbar protection system under 3- $\Phi$ symmetrical fault: a) voltage at PCC; b) DC link voltage; c) rotor speed; d) active power; e) reactive power; f) electromagnetic torque.

In Fig. 5(b), the DC link voltage rises from a nominal value of $1150 \mathrm{~V}$ to $4500 \mathrm{~V}$ without protection system, while the DC link voltage rises from a nominal value of $1150 \mathrm{~V}$ to $1530 \mathrm{~V}$ with protection system. In Fig. 5(c), the rotor speed increases at 3.2 p.u. without triggering the protection system, but approaches about 1.42 p.u. when the protection system is triggered. In Fig. 5(d), the active power value suddenly reduces zero without triggering the protection system during grid fault. In Fig. 5(e), in this case, the system draws reactive power at the 1 p.u. from the power grid. The value of active power reduces 0.2 p.u. form nominal rate with active crowbar and the value of reactive power increases 0.2 p.u. form nominal rate with active crowbar system.

In Fig 5(f), the electromagnetic torque value reduces 0.58 p.u. with triggering the protection, while the electromagnetic torque value suddenly reduces zero without triggering the protection system during grid fault. DC link voltage, rotor speed, active power, reactive power, and electromagnetic torque are seen to be enhanced due to the control action of the proposed active crowbar system. Symmetrical fault $3-\Phi$ is the most severe fault type compared to other fault types. Therefore, symmetrical fault is quite difficult to control during grid fault. Thus, as seen from the compared results, the proposed active crowbar provides full control of the PMSG to prevent from damaging effect during the symmetrical grid faults. The 
Electromagnetic torque of the without active crowbar is oscillating higher than with active crowbar. This corrected can be achieved with the improved control action and with rapid active crowbar triggering of the GSC controller. Thus, as seen from the compared results, the proposed active crowbar provides full control of the PMSG to prevent from damaging effect during unsymmetrical 3- $\Phi$ grid fault.

\section{B. Scenario 2}

Unsymmetrical fault $1-\Phi$ is the least severe fault type compared to other fault types. However, the unsymmetrical fault $1-\Phi$ is the most common type of grid fault in the system. Therefore, the unsymmetrical $1-\Phi$ fault is important to control during grid fault. For the same system, the simulation results of PMSG are observed without and with the active crowbar during an unsymmetrical $1-\Phi$ to ground fault between a phase and ground. The simulation results for DC link voltage, rotor speed, active power, reactive power, and electromagnetic toque with a single-phase symmetrical fault are given in Fig. 6.

In Fig. 6(a), one line fault is applied between $4.0 \mathrm{~s}$ and 4.1 s. In Fig 6(b), DC link voltage maintains nearly constant at $1150 \mathrm{~V}$ with active crowbar system during and after grid fault, the ripples reached nearly $1800 \mathrm{~V}$ without active crowbar system. In Fig. 6(c), the rotor speed remained almost 1.2 p.u. with active crowbar system during and after grid fault, but the value of the rotor speed is at 1.66 p.u. without active crowbar system. In Fig. 6(d), the active power value suddenly reduces 0.4 p.u. without triggering the protection system during grid fault. In Fig 6(e), in this case, the system draws reactive power at the 0.6 p.u. from the power grid. The value of active power maintains nearly constant at 1 p.u. with active crowbar and the value of reactive power maintains nearly constant at 0 p.u with active crowbar. In Fig. 6(f), the Electromagnetic torque of the without active crowbar is oscillating higher than with active crowbar. This corrected can be achieved with the improved control action and with rapid active crowbar triggering of the GSC controller. Thus, as seen from the compared results, the proposed active crowbar provides full control of the PMSG to prevent from damaging effect during unsymmetrical 1- $\Phi$ grid fault.

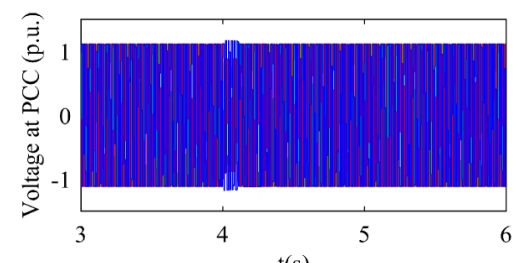

(a)

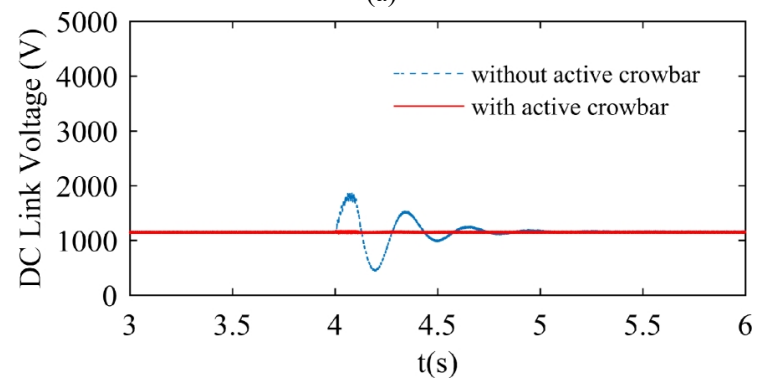

(b)

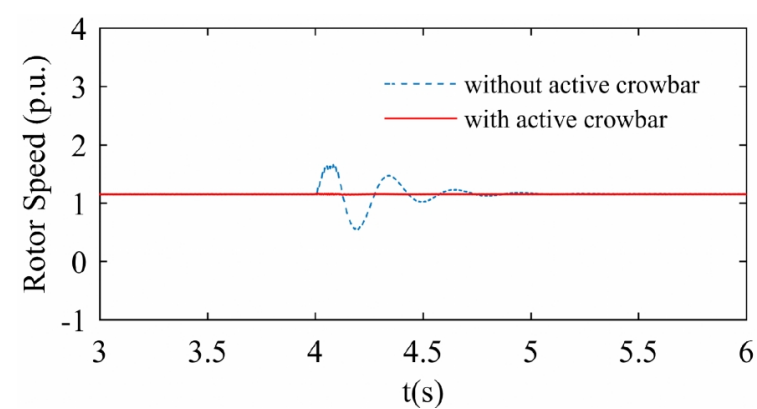

(c)

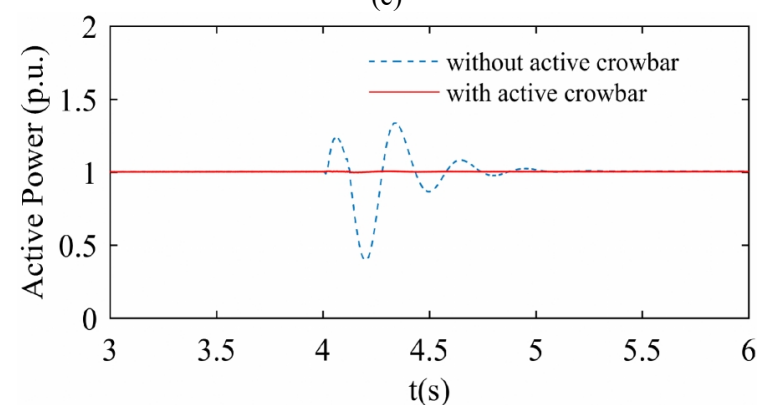

(d)

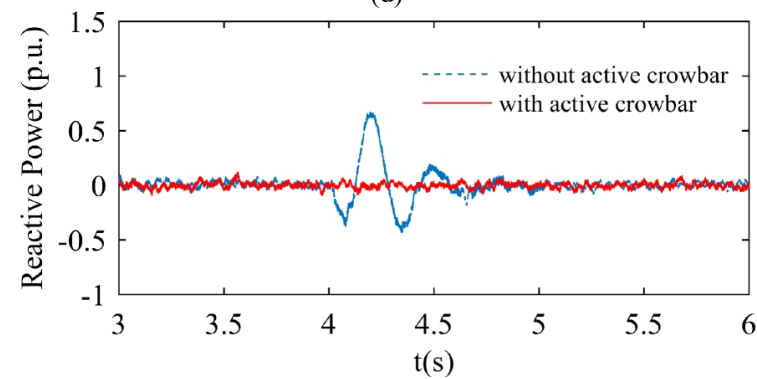

(e)

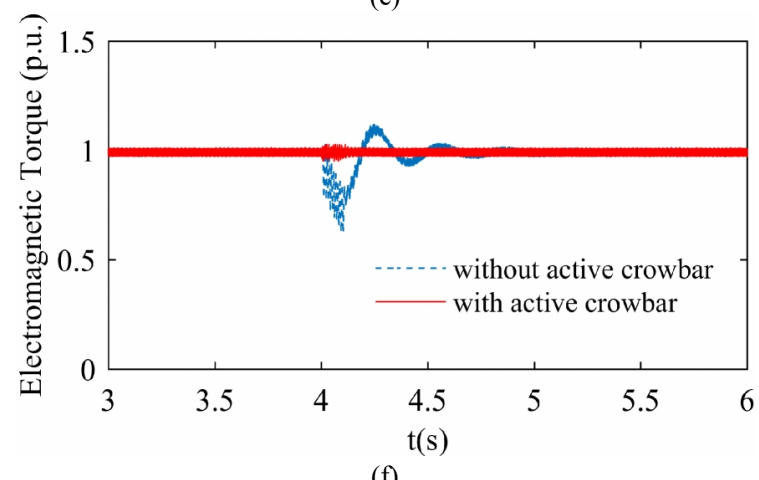

(f)

Fig. 6. Dynamic response of a 1.5 MVA PMSG with and without active crowbar protection system under 1- $\Phi$ symmetrical fault: a) voltage at PCC; b) DC link voltage; c) rotor speed; d) active power; e) reactive power; f) electromagnetic torque.

\section{CONCLUSIONS}

This paper presents the enhancement of fault-ride through capability of permanent magnet synchronous generator based on wind energy conversion system with active crowbar protection circuit during different fault conditions. Proposed control system and modelling of the whole system are illustrated with WECS based on 1.5-MW PMSG. Two different cases of symmetrical and unsymmetrical faults are analysed using an active crowbar design circuit and PMSGbased WECS in the Matlab/Simulink. The active crowbar system is implemented to improvement of fault-ride through capability of PMSG based on WECS during and after a different grid fault condition.

During a symmetrical 3- $\Phi$, the DC link voltage rises from 
$1150 \mathrm{~V}$ to $4500 \mathrm{~V}$ and unsymmetrical $1-\Phi$, the DC link voltage rises from $1150 \mathrm{~V}$ to $1800 \mathrm{~V}$ without active crowbar system. The active power suddenly reduces zero during a symmetrical $3-\Phi$ and the active power suddenly reduces 0.4 p.u. without the active crowbar system during an unsymmetrical 1- $\Phi$. However, the active power value maintains nearly 1 p.u. with active crowbar system in all voltage dip type and the DC link voltage maintains a nominal value of $1150 \mathrm{~V}$ with active crowbar system in all fault types.

The performance of the active crowbar system has very small settling time, peak value, and drop value compared to without the active crowbar system. The proposed active crowbar system has better performance compared to without the active crowbar system during different grid fault conditions. Finally, as clear from the compared results, the proposed active crowbar system provides full control of the PMSG to prevent from damaging effect during symmetrical and unsymmetrical grid faults.

\section{REFERENCES}

[1] Y. Li, Z. Xu, K. P. Wong, "Advanced control strategies of PMSGbased wind turbines for system inertia support", IEEE Trans. Power Systems, vol. 32, no. 4, pp. 3027-3037, 2017. DOI 10.1109/TPWRS.2016.2616171.

[2] Z. Zhang, F. Wang, J. Wang, J. Rodriguez, R. Kennel, "Nonlinear direct control for three-level NPC back-to-back converter PMSG wind turbine systems: experimental assessment with FPGA", IEEE Trans. Industrial Informatics, vol. 13, no. 3, pp. 1172-1183, 2017. DOI: $10.1109 /$ TII.2017.2678500.

[3] D. Xie, Y. Lu, J. Sun, C. Gu, "Small signal stability analysis for different types of PMSGs connected to the grid", Renewable Energy, vol. 106, pp. 149-164, 2017. DOI: 10.1016/ j.renene.2017.01.021.

[4] A. Bonfiglio, F. Delfino, F. Gonzalez-Longatt, R. Procopio, "Steadystate assessments of PMSGs in wind generating units", International Journal of Electrical Power \& Energy Systems, vol. 90, pp. 87-93, 2017. DOI: $10.1016 /$ j.ijepes. 2017.02.002.

[5] K. H. Kim, Y. C. Jeung, D. C. Lee, H. G. Kim, "LVRT scheme of PMSG wind power systems based on feedback linearization", IEEE Trans. Power Electronics, vol. 27, no. 5, pp. 2376-2384, 2012. DOI: 10.1109/TPEL.2011.2171999.

[6] B. Singh, S. N. Singh, L. Wang, "Electric grid connection and system operational aspect of wind power generation", Wind energy conversion system: technology and trends, pp. 267-293, 2012.

[7] S. Swain, P. K. Ray, "Short circuit fault analysis in a grid connected DFIG based wind energy system with active crowbar protection circuit for ride through capability and power quality improvement", International Journal of Electrical Power \& Energy Systems, vol. 84, pp. 64-75, 2017. DOI: 10.1016/ j.ijepes. 2016.05.006.

[8] J. Mohammadi, S. Afsharnia, S. Vaez-Zadeh, S. Farhangi, "Improved fault ride through strategy for doubly fed induction generator based wind turbines under both symmetrical and asymmetrical grid faults", IET Renewable Power Generation, vol. 10, no. 8, pp. 1114-1122, 2016. DOI: 10.1049/iet-rpg. 2015.0586.

[9] M. M. Mansouri, M. Nayeripour, M. Negnevitsky, "Internal electrical protection of wind turbine with doubly fed induction generator", Renewable and Sustainable Energy Reviews, vol. 55, pp. 840-855, 2016. DOI: 10.1016/j.rser. 2015.11.023.

[10] F. Valenciaga, R. D. Fernandez, "Multiple-input-multiple-output high-order sliding mode control for a permanent magnet synchronous generator wind-based system with grid support capabilities", in IET Renewable Power Generation, vol. 9, no. 8, pp. 925-934, 2015. DOI: 10.1049/iet-rpg.2014.0417.

[11] A. Moawwad, M. S. El Moursi, W. Xiao, "A novel transient control strategy for VSC-HVDC connecting offshore wind power plant", IEEE Trans. Sustainable Energy, vol. 5, no. 4, pp. 1056-1069, 2014. DOI: 10.1109/TSTE.2014.2325951.

[12] M. Popat, B. Wul, N. R. Zargari, "Fault ride-through capability of cascaded current-source converter-based offshore wind farm", IEEE Trans. Sustainable Energy, vol. 4, no. 2, pp. 314-323, 2013. DOI: 10.1109/TSTE.2012.2223246.

[13] S. Tohidi, P. Tavner, R. McMahon, H. Oraee, M. R. Zolghadri, $\mathrm{S}$. Shao S, et al. "Low voltage ride-through of DFIG and brushless DFIG: similarities and differences", Electric Power System Research, vol. 110, pp. 64-72, 2014. DOI: 10.1016/j.epsr.2013.12.018.

[14] C.-M. Hong, C.-H. Chen, C. S. Tu, "Maximum power point trackingbased control algorithm for PMSG wind generation system without mechanical sensors", Energy Conversion and Management, vol. 69, pp. 58-67, 2013. DOI: 10.1016/j.enconman.2012.12.012.

[15] J. Yao, M. Yu, W. Gao, X. Zeng, "Frequency regulation control strategy for PMSG wind-power generation system with flywheel energy storage unit", IET Renewable Power Generation, vol. 11, no. 8, pp. 1082-1093, 2017. DOI: 10. 1049/iet-rpg.2016.0047.

[16] A. M. Eltamaly, H. M. Farh, "Maximum power extraction from wind energy system based on fuzzy logic control", Electric Power Systems Research, vol. 97, pp. 144-150, 2013. DOI: 10.1016/j.epsr.2013.01.001.

[17] A. Calle-Prado, S. Alepuz, J. Bordonau, P. Cortes, J. Rodriguez, "Predictive control of a back-to-back NPC converter-based wind power system", IEEE Trans. Industrial Electronics, vol. 63, no. 7, pp. 4615-4627, 2016. DOI: 10. 1109/TIE.2016.2529564.

[18] W. Guo, F. Liu, D. He, J. Si, R. Harley, S. Mei, "Reactive power control of DFIG wind farm using online supplementary learning controller based on approximate dynamic programming", Int. Joint Conf. Neural Networks (IJCNN 2014), Beijing, China, 2014. DOI: 10.1109/IJCNN.2014.6889871.

[19] W. Guo, F. Liu, J. Si, D. He, R. Harley, S. Mei, "Approximate dynamic programming based supplementary reactive power control for DFIG wind farm to enhance power system stability", Neurocomputing, vol. 170, pp. 417-427, 2015. DOI: 10.1016/j.neucom.2015.03.089.

[20] A. Gencer, "Modelling and analysis of operation PMSG based WECS under different load conditions", in 8th Int. Conf. Electronics, Computers and Artificial Intelligence (ECAI 2016), Ploiesti, 2016, pp. 1-6. DOI: 10.1109 /ECAI.2016.7861198.

[21] S. Yang, T. Zhou, D. Sun, Z. Xie, X. Zhang, "A SCR crowbar commutated with power converter for DFIG-based wind turbines", International Journal of Electrical Power \& Energy Systems, vol. 81, pp. 87-103, 2016. DOI: 10. 1016/j.ijepes.2016.01.039. 